\title{
INVENTARISASI SAINS ASLI SUKU MALIND: UPAYA DALAM PENGEMBANGAN KURIKULUM IPA KONTEKSTUAL PAPUA BERBASIS ETNOSAINS
}

\author{
Supriyadi dan Evy Nurvitasari \\ Universitas Musamus Merauke \\ e-mail: Supriyadi_fkip@unmus.ac.id
}

\begin{abstract}
Abstrak
Penelitian ini bertujuan untuk menginventarisasi sains asli yang tumbuh dan berkembang dalam suku Malind (Papua) sebagai bahan dalam pengembangan Kurikulum IPA berbasis Etnosains. Penelitian ini dilaksanakan di kampung-kampung yang berada diwilayah kabupaten Merauke yang didiami oleh masyarakat suku Malind. Data tentang sains asli pada penelitian ini diperoleh dari hasil observasi dilapangan, partisipan, wawancara mendalam dan dokumentasi selama hasil penelitian, selanjutnya dilakukan triangulasi. Hasil Penelitian ini menunjukkan terdapat 11 topik sains asli yang memiiki penjelasan logis secara ilmiah dan dapat digunakan dalam pembelajaran IPA SMP. Hasil dari penelitian ini, berupa data tentang sains asli suku Malind dapat dijadikan acuan serta ilustrasi dalam pembelajaran sains di sekolah. Serta dari penelitian ini muncul rekomendasi bagi Kementerian Pendidikan khususnya Dinas Pendidikan dan Kebudayaan Kabupaten Merauke untuk mengakomodasi sains asli suku Malind agar dapat diintegrasikan dalam pembelajaran sains disekolah.
\end{abstract}

Kata kunci: Inventarisasi, Sains Asli, Suku Malind, Kontekstual, Etnosains

\begin{abstract}
This study aims to inventory the authentic science grow and developed in one of Papua Tribes; Malind, as materials in the development of the Ethnoscience-based Curriculum. This research was conducted in villages around Merauke regency which are inhabited by Malind tribal community. Data of the authentic science in this study were obtained from the results of field observations, participants, in-depth interviews, documentation, and triangulation. The results of this study indicated eleven (11) authentic science materials with logical or scientific explanation which can be used for science learning in junior high school. The results of this study can be used as a reference and illustration in science learning at school. Furthermore, this could also be used as a subject of recommendation emerged for the Ministry of Education, especially the Education and Culture Office of Merauke Regency to accommodate the authentic materials from Malind tribe to be integrated into science learning at schools.
\end{abstract}

Keywords: Inventory, Authentic Science, Malin Tribe, Contextual, Ethnoscience

\section{PENDAHULUAN}

Pemberantasan tuna aksara dan penerapan pendidikan kurikulum kontekstual Papua merupakan salah satu instruksi presiden (Inpres Nomor 9 tahun 2017) dibidang pendidikan tentang percepatan pembangunan kesejahteraan di Propinsi Papua, termasuk 
Kabupaten Merauke. Dalam rangka mendukung pelaksanaan rencana aksi tersebut maka penyusunan kurikulum IPA berbasis etnosains dengan latar belakang sains asli papua menjadi sebuah keharusan. Untuk itu perlu dilakukan penelitian awal guna menggali informasi tentang sains asli (Indigenous Scince) yang tumbuh dan berkembang di propinsi Papua.

Pembelajaran IPA (sains) masih menjadi pembelajaran yang dianggap sulit bahkan cenderung dihindari peserta didik. Hal ini membuat pemahaman konsep peserta didik terhadap pembelajaran IPA menjadi kurang baik. Salah satu alasan pembelajaran IPA dianggap sulit karena paradigma yang berkembang pada peserta didik. IPA diidentikkan sebagai pelajaran yang hanya dipenuhi rumus matematis dan tidak memiliki manfaat dalam kehidupan sehari-hari. Faktanya, hampir seluruh segi kehidupan dipengaruhi oleh aktifitas sains (Fisika, Biologi, dan Kimia). Selain alasan diatas, pembelajaran IPA menjadi sulit untuk dipahami peserta didik karena terdapat kesenjangan antara sains yang di pelajari disekolahan dengan budaya masyarakat indonesia (Sarwanto, Budiharti, \& Fitriana, 2010). Sains yang dipelajari disekolah merupakan sains modern yang dilatar belakangi oleh budaya barat. Poedjiadi menyatakan apabila pengetahuan sains yang dipelajari disekolah bisa dirasakan manfaatnya bagi kehidupan siswa, maka siswa akan termotivasi untuk mempelajari lebih banyak tentang pengetahuan itu (Poedjiadi, 2010).

Kabupaten Merauke merupakan kabupaten yang berada di ujung timur Republik Indonesia. Suku asli yang mendiami kabupaten Merauke ini adalah suku Malind. Seperti halnya suku-suku lain yang mendiami pulau Papua, maka suku Malind juga memiliki tradisi yang kaya. Tradisi tersebut masih terjaga hingga kini dan sudah membudaya. Peneliti meyakini, dari sekian banyak budaya yang ada pada suku Malind terdapat budaya yang mengandung nilai sains asli (indegenous sains). Sains asli (indigenous sains) yang telah membudaya dan terintegrasi dengan aktifitas sehari-hari ini biasa juga dikenal dengan etnosains. Berberapa peneliti mendefinisikan etnosains sebagai sebuah studi mendalam terhadap sistem pengetahuan yang dikembangkan berdasarkan perspektif budaya setempat yang berkaitan dengan suatu objek atau aktifitas berdasarkan fenomena alam (Shidiq, 2016). Sementara itu menurut Rahayu dan Sudarmin, etnosains merupakan suatu aktifitas mentransformasikan antara sains asli dengan sains ilmiah (Rahayu \& Sudarmin, 2015). Jika dalam pembelajaran sains disekolah dapat mengaitkan antara kerja ilmiah sains (sains modern) dan sains asli (indigenous sains) diharapkan peserta didik dapat lebih mudah dalam memahami konsep sains. Kemampuan peserta didik dalam memahami konsep ini akan meningkatkan mutu dari pendidikan sains itu sendiri.

Diharapkan dengan melakukan inventarisasi sains asli (indigenous sains) tersebut, dapat menjadi langkah awal untuk nantinya dikembangkan kurikulum IPA 
berbasis etnosains yang bernuansa kearifan lokal suku Malind (Papua). Penelitian ini, juga diharapkan dapat menjadi bagian dari proses pelestarian budaya suku Malind yang mulai terpinggirkan ditanah mereka sendiri. Selain itu, penelitian ini diharapkan dapat mendukung program pemerintah melalui instruksi presiden nomor 9 tahun 2017 tentang percepatan pembangunan kesejahteraan di Propinsi Papua, termasuk Kabupaten Merauke. Diharapkan melalui penelitian ini akan diperoleh referensi-referensi dasar dalam penyusunan kurikulum pendidikan kontektual Papua khusunya untuk pembelajaranan IPA terpadu di SMP.

\section{METODE}

Jenis penelitian yang digunakan adalah penelitian kualitatif dengan menggunakan pendekatan etnosains. Peneliti secara intensif ikut berpartisipasi secara aktif di lapangan dengan mencatat dan menganalisis serta merepresentasi segala temuan yang ditemukan di lapangan. Pendekatan etnosains digunakan agar dapat menganalisis secara mendalam segala bentuk sains asli yang ditemukan pada masyarakat asli suku Malind. Pengumpulan data dilakukan dengan melakukan wawancara secara mendalam dengan masyarakat asli Suku Malind (Papua). Kemudian data dianalisis dengan merepresentasikan hasil survei (wawancara) yang dibandingkan dengan penjelasan secara ilmiah (sains modern).

\section{HASIL DAN PEMBAHASAN}

Pada pelaksanaan penelitian, peneliti mengekplorasi sains asli masyarakat suku Malind. Berdasarkan data yang berhasil dikumpulkan maka ditemukan beberapa sains asli yang tumbuh dan berkembang dimasyarakat. Sains asli tersebut kemudian diinterpretasikan dengan mengacu pada hasil observasi mendalam terkait budaya masyarakat suku Malind dengan mengikuti kaidah metode ilmiah. Adapun temuan sains asli tersebut seperti ditampilkan pada Tabel 1. 
Tabel 1. Sains asli ditinjau penjelasan sains asli dan penjelasan ilmiah

\begin{tabular}{|c|c|c|c|}
\hline No. & Aktivitas Sains asli & Penjelasan sains asli & Penjelasan ilmiah \\
\hline 1 & $\begin{array}{l}\text { Kegiatan Kahwanuk (mengukur) } \\
\text { ruas bambu saat membuat busur } \\
\text { panah }\end{array}$ & $\begin{array}{l}\text { Mengukur menggunakan } \\
\text { satuan muk (ruas pada } \\
\text { bambu) dalam pembuatan } \\
\text { busur }\end{array}$ & $\begin{array}{l}\text { Pengukuran dengan } \\
\text { satuan tidak baku }\end{array}$ \\
\hline 2 & $\begin{array}{l}\text { Pelaksanaan sasi (larangan) untuk } \\
\text { mengambil hasil bumi (Tumbuhan } \\
\text { dan hewan) saat pemilik lahan } \\
\text { meninggal dunia sampai waktu } \\
\text { tertentu dengan memasang tep } \\
\text { (tanda larangan) }\end{array}$ & $\begin{array}{l}\text { Pelestarian dusun sagu, } \\
\text { dusun kelapa dll. Milik } \\
\text { orang yang meninggal }\end{array}$ & $\begin{array}{l}\text { Pelestarian } \\
\text { lingkungan melalui } \\
\text { konservasi adat }\end{array}$ \\
\hline 3 & $\begin{array}{l}\text { Meramu bahan alam untuk } \\
\text { mendapatkan pola warna tertentu } \\
\text { dalam seni ukir (Nangge) }\end{array}$ & $\begin{array}{l}\text { Meramu dan mencampurkan } \\
\text { beberapa bahan alam seperti } \\
\text { arang, lumpur hitam, kulit } \\
\text { kayu, tanah liat, batu merah, } \\
\text { kulit siput, lumpur putih, dll } \\
\text { untuk mendapatkan warna } \\
\text { Hitam (konaihi), merah } \\
\text { (dohi), dan putih (koihi) }\end{array}$ & $\begin{array}{l}\text { Pemanfaatan } \\
\text { karakteristik zat, } \\
\text { perubahan fisika dan } \\
\text { kimia pada zat }\end{array}$ \\
\hline 4 & Pembuatan Sagu sep & $\begin{array}{l}\text { Sagu yang diolah/dibakar } \\
\text { dengan batu yang panas } \\
\text { (dibakar) }\end{array}$ & $\begin{array}{l}\text { Perpindahan kalor } \\
\text { secara konduksi dari } \\
\text { batu ke adonan sagu }\end{array}$ \\
\hline 5 & $\begin{array}{l}\text { Wet (siklus/Interaksi makhluk hidup } \\
\text { dengan lingkungan }\end{array}$ & $\begin{array}{l}\text { Proses mengamati ciri-ciri } \\
\text { perubahan musim melalui } \\
\text { interaksi makhluk hidup } \\
\text { dengan lingkungan }\end{array}$ & $\begin{array}{l}\text { Tingkah laku } \\
\text { makhluk hidup yang } \\
\text { menandai perubahan } \\
\text { musim }\end{array}$ \\
\hline 6 & $\begin{array}{l}\text { Pemberian nama marga/klen } \\
\text { berdasarkan nama hewan atau } \\
\text { tumbuhan misalnya } \\
\text { (basikbasik/babi, Ndiken/burung) }\end{array}$ & $\begin{array}{l}\text { Pemberian nama ini } \\
\text { sekaligus sebagai penjaga } \\
\text { pelesatarian hewan atau } \\
\text { tumbuhan tertentu }\end{array}$ & $\begin{array}{l}\text { Menjaga kelestarian } \\
\text { lingkungan }\end{array}$ \\
\hline 7 & $\begin{array}{l}\text { Penggunaan tangguh (Jenis-jenis } \\
\text { tanaman obat) dalam mengobati } \\
\text { penyakit dan makan pinang }\end{array}$ & $\begin{array}{l}\text { Meramu obat-obatan } \\
\text { tradisional seperti kencur } \\
\text { (Ukap), Pakis (Bu'u), dll }\end{array}$ & $\begin{array}{l}\text { Pemanfaatan sifat } \\
\text { bahan terhadap } \\
\text { kesehatan manusia }\end{array}$ \\
\hline 8 & $\begin{array}{l}\text { Penggunaan kulit kerang (kulit bia) } \\
\text { sebagai pemarut kelapa }\end{array}$ & $\begin{array}{l}\text { Mempermudah dalam } \\
\text { memarut kelapa }\end{array}$ & $\begin{array}{l}\text { Pemanfaatan } \\
\text { pesewat sederhana }\end{array}$ \\
\hline 9 & $\begin{array}{l}\text { Wati (minuman memabukkan) } \\
\text { sebagai unsur pelengkap dalam } \\
\text { upacara adat }\end{array}$ & $\begin{array}{l}\text { Wati sebagai simbol } \\
\text { kewibaan bagi laki-laki suku } \\
\text { Malind }\end{array}$ & $\begin{array}{l}\text { Tumbuhan yang } \\
\text { mengandung unsur } \\
\text { memabukkan }\end{array}$ \\
\hline 10 & $\begin{array}{l}\text { Penggunaan alat musik seperti tifa } \\
\text { dalam acara adat }\end{array}$ & $\begin{array}{l}\text { Ukuran tifa akan } \\
\text { mempengarungi besar } \\
\text { kecilnya bunyi selain itu tifa } \\
\text { harus menggunakan kulit } \\
\text { kangguru (saham) }\end{array}$ & $\begin{array}{l}\text { ukuran tifa dan } \\
\text { penggunaan kulit } \\
\text { kangguru (saham) } \\
\text { mempengaruhi } \\
\text { resonansi bunyi }\end{array}$ \\
\hline 11 & $\begin{array}{l}\text { Larangan menikah dengan marga } \\
\text { tertentu (misalnya Laki-laki Ndiken } \\
\text { dilarang menikah dengan wanita } \\
\text { Gebze) }\end{array}$ & $\begin{array}{l}\text { Ndiken dan Gebze } \\
\text { merupakan sat nenek } \\
\text { moyang, jika tetap menikah } \\
\text { generasinya tidak bagus }\end{array}$ & $\begin{array}{l}\text { Aturan pada sistem } \\
\text { reproduksi, dimana } \\
\text { akan ada kelainan } \\
\text { pada anank hasil } \\
\text { perkawinan sedarah }\end{array}$ \\
\hline
\end{tabular}

Agar hasil yang diperoleh pada penelitian ini valid, maka dilakukan validasi data melalui proses triangulasi data. Data yang diperoleh dari masyarakat Suku malind kemudian dibandingkan dengan data yang diperoleh dari studi pustaka dan wawancara dengan penggiat budaya Suku Malind dari Dinas Pendidikan dan Kebudayaan Merauke. Data yang dimaksud merupakan data hasil observasi dan identifikasi secara langsung 
pada kelompok masyarakat suku Malind. Kelompok masyarakat suku Malind yang menjadi sumber informan berasal dari kampung Lampu satu, Payum, Wasur, Kaiburse dan Domande. Informasi awal yang diperoleh, Suku malind adalah suku yang bermukim diwilayah pantai dan pedalaman selatan tanah Papua. Berdasarkan kepustakaan Belanda dan Indonesia, penyebutan Malind jarang digunakan. Penyebutan kata yang sering digunakan adalah Marind. Hal ini sesuai dengan penyampaian hasil penelitian sebelumnya yang menyatakan bahwa penggunaan kata Marind lebih disebabkan oleh perubahan intonasi para pendatang (Peday, Kanggam, Mahuze, Yosep, \& Ronggo, 2015).

Hasil pengumpulan data awal yang diperoleh, didapatkan bahwa masyarakat suku Malind tidak memiliki standar pengukuran baku yang digunakan dalam pengukuran. Buku digunakan untuk menyatakan besaran busur panah yang dibuat.

Peneliti : Bagaimana dengan alat ukur dan satuan yang digunakan suku Malind?

N01 : Buku yang ruas-ruasnya itu seberapa panjang busur itu,mereka hitung itu ruas, dan itu mengukur kemampuan orang kalau orang itu badan besar tinggi ya busur harus lewat manusia itu,berarti biasa $10-12$ ruas sehingga kalau panah lewat tembus sebelah,semakin kecil berarti untuk anak-anak kecil semakin kecil sekali,6 ruas saja berarti itu untuk anak kecil dan busur itu di peruntukannya tidak sama dengan hewan besar berarti oh untuk panah ikan saja ini busur kecil, panah-panah ikan bulanak kah ikan di rawa-rawa

Peneliti : berarti pada dasarnya mereka tidak memiliki alat untuk mengukur?

N01 : Tidak ada,hanya mewakili itu,sebenarnya ada berapa ruas itu bambu, muk namanya. kalau dengan bahasa marind mengukur itu kahwanuk artinya ukurnya di ruasnya ada berapa,karena manusianya sangat besar

Berdasarkan pernyataan narasumber, diperoleh informasi bahwa terdapat budaya mengukur (kahwanuk) yang biasa digunakan dalam aktivitas membuat busur panah. Satuan pengukurannya adalah buku (ruas) bambu.

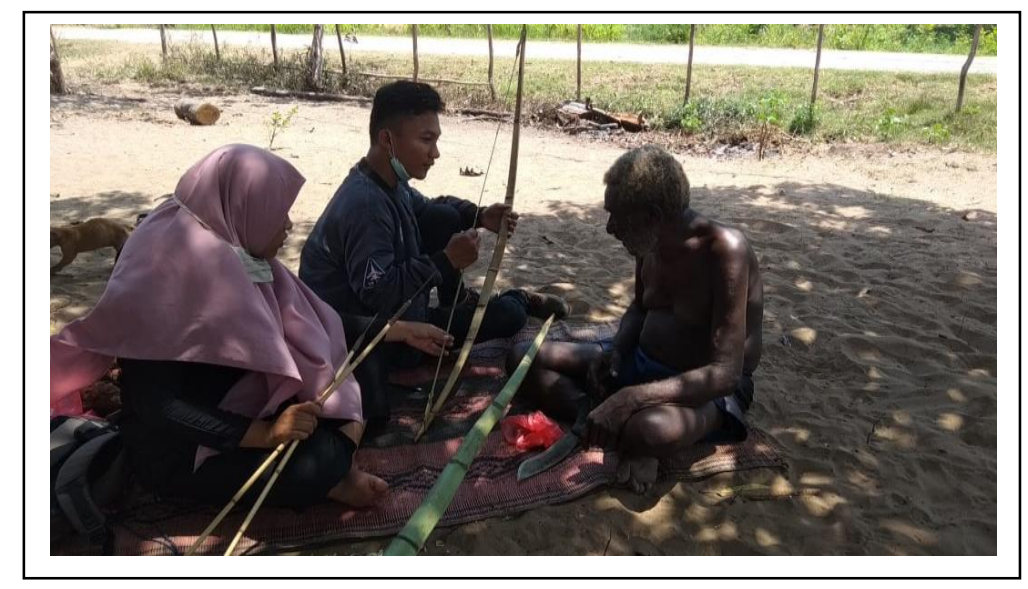

Gambar 1. Penerapan pengukuran dengan satuan buku untuk mengukur besar busur panah 
Pada aktivitas harian suku Malind, masyarakat suku Malind mengenal istilah tep atau yang biasa dikenal dengan sasi (kula). Sasi atau Tep ini merupakan larangan yang diberlakukan apabila salah satu anggota keluarga meninggal. Larangan ini bermaksud agar tidak menangkap hewan atau memanfaatkan tumbuhan disekitar tanda larangan tep.

N01 : Sasi itu sama dengan kata larangan. Itu bisa ada apabila anggota keluarga ada meninggal. Lalu setelah 40 hari mereka ada tanam sasi di dusun sagu atau dusun kelapa atau di rawa, ini dengan maksud supaya selama satu tahun tidak boleh diganggu ikan atau hewan ditempat itu karena dia akan menjadi daerah konservatif terbatas.

Temuan yang didapat dalam penelitian ini memperlihatkan tentang sains asli/warisan budaya lokal yang mengandung unsur sains yang terkait dengan konservasi. temuan memperkuat hasil temuan sebelumnya yang dilakukan dikabupaten Cirebon. Dimana peningkatan konservasi lingkungan dan potensi lokal sangat dipengaruhi oleh pembelajaran berbasis warisan budaya lokal (Tresnawati, 2018).

P01 : ... orang tanam sasi toch. Kalo ada yang meninggal. Jadi orang tidak boleh petik sagu, kelapa. Itu tidak boleh petik sampai, satu tahun sana. Baru boleh petik kelapa yang tua.

Suku Malind merupakan suku yang mendiami daratan Papua wilayah selatan. Suku Malind juga memiliki peradaban dengan nilai kesenian yang tinggi. Mereka juga mengenal seni ukir dan untuk menghiasi hasil ukiran yang dibuat mereka memberikan sentuhan warna yang memiliki filosofi sesuai keyakinan Suku Malind. Warna memiliki digunakan untuk memperkaya unsur karya seni yang dihasilkan. Proses pewarnaan ini di sebut dengan nangge. Nangge adalah proses memperoleh warna dari alam dengan cara mencampurkan/meramu secara tradisional. Warna khas yang ada dalam kebudayaan suku Malind adalah hitam (kunaihi), merah (dohi), dan putih (koihi). Suku Malind memanfaatkan bahan-bahan yang ada disekitar mereka sebagai bahan baku utama dalam pembuatan warna.

N01 : ... Nah ini bahan-bahannya, bahan baku yang pertama hitam itu dari darah ... darah hewan dicampur apa ... dicampur arang. Kemudian yang berikut ini tanah liat ditambah dengan kulit kayu (nggalasal). Itu tanah khusus, tidak ada di tempat lain. Hitam yang berikut itu dari ubur-ubur, tergantung tempatnya toch, kalo pesisir ubur-ubur. Kalo tinggal di hutan berarti kulit kayu. Sedangkan warna putih itu dari kapur. Kemudian kuning, warna kuning itu kulit kayu dicampur kapur nanti warnanya kuning, selain itu pake yang kita bilang bidabet (kunyit). Kalo dapat warna merah juga kunyit dicampur kapur. lalu warna merah didapat dari darah, tanah liat. 
Penelitian lain terkait zat aditif berbasis etnosains seperti pada penelitian (Tresnawati, 2018), yang menyebutkan bahwa masyarakat tentang pemanfaatan tumbuhan sebagai warna dasar dalam pembuatan batik merupakan budaya lokal yang mengandung unsur sains. Sehingga penulis dapat menginterpretasikan bahwa penggunaan tumbuhan, hewan dan bahan lain dari alam sebagai bahan baku wara pada suku Malind merupakan sains asli yang ada pada suku Malind

Suku Papua bagian selatan (Malind) juga mengenal istilah bakar batu. Suku Malind menyebut istilah bakar baku dengan sep. Penerapan sep sendiri dapat kita temukan pada pembuatan sagu sep. Sagu sep adalah makanan olahan sagu yang dibakar menggunakan batu panas (batu bakar/sep).

N01 : ... istilah bakar batu itu dari utara (Waropen). Kalo disini sep. Sep ya, sep itu batu dibakar kemudian ada adonan sagu dan kelapa yang dimasak dengan cara batu dibakar.

Peneliti : Batunya didapat dari mana?

N01 : Batu banyak mo, musim panas ada tanah-tanah yang sudah mengeras, itu yang jadi batu, di Wambi banyak batu, di onggari banyak batu. Di pantai itu, karang-karang itu. Jadi tergantung malind pantai atau malin hutan.

Dari proses pembuatan Sagu sep siswa dapat diajarkan konsep perpindahan kalor. Dalam Sagu sep terdapat penerapan konsep perpindahan kalor secara konduksi. Sampai saat ini, proses pembuatan sagu dengan batu yang di bakar (sagu sep) masih sering dilakukan dimasyarakat.

Suku Malind juga mengenal aktivitas membaca kondisi alam (wet). Aktifitas membaca kondisi alam ( wet) merupakan kegiatan memperhatikan perubahan tingkah laku makhluk hidup yang berada dilingkungan tempat tinggal.

Peneliti : kalo istilah yang dipakai suku marind untuk melihat tingkah laku makhluh hidup bapak?

N01 : istilah untuk siklus itu wet.

Wet adalah aktifitas untuk membaca siklus musim dengan melihat tingkah laku hewan yang ada di lingkungan. Pada bebrapa responden dan narasumber ahli menyebutkan contoh yang berbeda. Misalnya pada suku Malind pantai melihat tingkah laku hewan laut. Sedangkan suku Malind yang tinggal dihutan melihat tingkah laku burung yang mencari makan di rawa.

P02 : tidak mejaring hari ini. Karena air panas toch. Kalo musim panas, Udang kurang. Kalo air dingin udang naik. Mama juga biasa ada yag dari kota 
bilang, "mama ada udang kah?" ado... tidak ada karena cuaca panas jadi cari biya saja.

Narasumber menyatakan

N01 : burung-burung yang tadi bilang itu ada datang bulan ini (menunjuk bulan april-mei). Ini artinya angin laut mo datang, air mo kering, mereka cari

makan cepat. Kalo bulan juli, sudah kering mereka cari makan di pantai

Aktivitas sains asli suku Malind dengan maksud untuk melestarikan sumber daya alam yang ada juga dapat dilihat pada pemberian nama marga dalam suku Malind. Mereka menggunakan nama hewan atau tumbuhan pada nama marga. Dalam filosofi suku malind, nama tersebut adalah totem yang harus mereka jaga. Misalnya marga Gebze (burung taon-taon), marga Kaize (kasuari, gambir), marga Mahuze (Mboha/sagu), marga Balagaize (Elang/buaya), marga Samkakai (saham/kangguru), marga Ndiken (bangau/kura-kura), marga Basik-Basik (babi). Selain itu, setiap marga memiliki tanggung jawa untuk menjaga totemnya masing-masing. Totem adalah tumbuhan/hewan yang diidentifikasikan pada sibol diri. Totem diyakini sebagai perwujudan roh leluhur yang wajib mereka jaga. Setiap marga memiliki totemnya masing-masing. totem marga Samkakai adalah kanguru. Marga Mahuze memiliki totem sagu, marga Gebze memiliki totem kelapa, Kaize memiliki totem kasuari. Burung elang adalah totem marga Balagaize. Burung ndik hitam dan wati menjadi totem marga Ndiken. Sedangkan Basik-basik memiliki totem babi (Prasetya, 2012). Hal ini diperkuat dengan hasil wawancara dengan warga suku Malind yang mendiami pantai di Kampung Payum.

Peneliti : katanya kalo kelapa, pisang itu simbol dari marga disini. Itu seperti apa?

P03 : oh iya wati itu totem untuk ndiken, kelapa untuk mahuze.

Sama halnya dengan warisan budaya lokal di daerah lain, masyarakat suku Malind juga mengenal pengobatan tradisional dengan meramu tumbuhan obat (ilmu Farmakologi). Istilah yang digunakan masyarakat suku Malind dalam penyebutan jenis tumbuhan obat-obatan tradisional adalah tangguh de dakum kutamad (Ndiken, 2013). Suku Malind menggunakan berbagai macam tumbuhan obat tradisional seperti kencur (ukap), Pakis (bu'u), mengkudu (gidu), gondang (epem), kayu timur (mumbala) dan lainlain untuk mengobati berbagai macam penyakit.

Peneliti : apakah suku Malind biasa meramu tumbuhan menjadi obat?

N01 : oh iya farmakologi, kalo di Malind disebut tangguh. Kalo untuk orang Malind, menggkudu itu obat. Orang Malind bilang gidu.

Kegiatan meramu tanaman obat yang ada di suku Malind, dapat dikaitkan dengan kemampuan manusian untuk mengetahui sifat suatu bahan, pemanfaatannya serta pengaruh pemanfaatannya dalam kehidupan sehari-hari. Kebiasaan lain yang memiliki 
kaitan dengan sifat suatu bahan adalah penggunaan daun kelapa kering yang dibakar untuk di jadikan pupuk.

Peneliti : kalo musim panas begini bapak bertani kah tidak?

N01 : ah tidak....tunggu hujan kalo sekarang kan harus cari daun kelapa dorang untuk dibakar hujan langsung tanam

Peneliti : daun kelapa dibakar untuk jadi pupuknya?

N01 : iya, untuk jadi pupuk

Hasil wawancara menunjukkan bahwa masyarakat suku Malind telah mengenal cara membuat pupuk organik melalui hasil pembakaran sampah alami. Siswa dapat membandingkan kebiasaan masyarakat suku Malind dengan masyarakat modern yang memanfaatkan sifat suatu zat untuk dimanfaatkan serta untuk kesehatan manusia.

Suku Malind khususnya Malind pantai juga sudah memanfaatkan berbagai perkakas yang berasal dari alam yang dimanfaatkan sebagai pesawat sederhana seperti penggunaan kulit biya (kerang) sebagai alat untuk memarut Kelapa.

Peneliti : Bapak, kami liat Malind pantai (Orang Malind di daerah pantai) buat sagu sep campur denga kelapa, bagaimana parutnya?

N01 : iya, itu pake siput, pake kulit biya (kerang)

Selanjutnya ditemukan kebiasaan meminum minuman keras dari perasan tumbuhan wati. Wati merupakan salah satu unsur pelengkap yang harus ada dalam acara perkawinan suku Malind. Minuman Wati dihasilkan dari perasan daun Wati dan merupakan simbol kewibawaan.

Masyarakat suku Malind juga mengenal alat musik. Alat musik yang paling terkenal adalah tifa. Tifa merupakan alat musik pukul yang buat dari kulit kangguru. Menurut masyarakat suku Malind, pembuatan tifa tidak boleh menggunakan kulit hewan lain selain kangguru. Secara sains ilmiah tipis tebalnya kulit hewan akan mempengaruhi resonansi bunyi yang dihasilkan. Sedangkan menurut salah seorang masyarakat suku Malind, kangguru digunakan karena ...tifa pake kulit kangguru, karena kalo kangguru bunyinya bisa nyaring...berdasarkan pernyataan ini maka dapat diketahui bahwa masyarakat suku Malind telah memanfaatkan kulit kangguru untuk menghasilkan resonansi bunyi.

Informasi akhir yang didapatkan dari penelitian ini terkait dengan larang menikah antara marga tertentu. Berdasarkan penelitian sebelumnya, dinyatakan bahwa perkawina ideal masyarakan Malind anim terjadi antara tiga paruh masyarakat (moiety). Moiety yang dimaksud yaitu Uhyuboand, Gebze dan Watilik (Samkakai, Hollenger, \& Ndiken, 2013).

Peneliti : pernikahan di Malind bagaimana aturannya? Katanya ada larangan nikah dengan marga tertentu? 
N01 : itu benar, karena ini ada ini to, [...] ini marga Mahuze ada marga Gebze itu harus kawin zigzak. Gebze tidak boleh menikah dengan Gebze. Karena itu moyangnya satu

Peneliti : konsekuensinya apa?

N01 : itu tidak boleh. Yang rusak mental anak. Turunannya tidak bagu. Itu hukum karmanya berlaku dari nenek moyang, yang hancur generasi.

Larangan pernikahan dengan kekerabatan yang dekat juga dikenal pada pengembangan sains modern. Dimana kita mengenal ilmu tentang gen. Hal ini menunjukkan bahwa sains asli terkait dengan reproduksi juga sudah dikenal pada suku Malind.

Sains asli yang ditemukan pada masyarakat Suku Malind terkait dengan kehidupan sehari-hari seperti pembuatan perkakas, kesenian, upacara adat, perilaku hidup, interaksi antara manusia dan manusia ataupun antar manusia dan alam. Segala bentuk sains asli ini, ada yang masih dipertahankan dan ada yang mulai terkikis oleh zaman. Untuk dapat terus menjaga dan melestarikan sains asli ini, perlu ada kajian yang dapat menghubungkan antara sains asli yang berdasar kepada pengalaman dan sains barat yang sudah berupa konsep, prinsip, teori ataupun hukum yang telah teruji di laboratorium. Langkah untuk menghubungkan dua bentuk pengetahuan sains ini diharapkan akan mampu memberikan nuansa baru dalam pembelajaran IPA (sains) dimasa mendatang sesuai dengan temuan-temuan penelitian sebelumnya yang telah dilakukan didaerah lain (Aikenhead \& Jegede, 1999; Osman \& Har, 2013; Poedjiadi, 2010; Rahayu \& Sudarmin, 2015; Rosyidah, Sudarmin, \& Kusoro, 2015; Sarwanto et al., 2010; Sarwanto, Sulistyo, Prayitno, \& Pratama, 2014; Shidiq, 2016; Suastra, 2010; Suja, 2011; Supriyadi, Haeruddin, \& Nurjannah, 2016).

\section{SIMPULAN}

Berdasarkan uraian dari hasil dan pembahasan, maka dapat ditarik beberapa kesimpulan berikut ini. Pertama, sains asli yang ditemui dalam budaya suku Malind merupakan suatu pengalaman kongkrit yang diperoleh dari interaksi antara manusia dan lingkungan. Serta tradisi tersebut terus tumbuh dan berkembang menjadi warisan budaya yang diturunkan secara turun temurun. Kedua, sains asli yang menjadi warisan budaya tersebut dicoba untuk diinterpretasikan sehingga dapat dijadikan rujukan dan diakomodasi untuk menjadi bahan dasar pembuatan perangkat kurikulum IPA di SMP. Ketiga. Pembelajaran sains disekolah hendaknya perlu untuk memperhatikan sains asli yang berkembang di sekitar lingkungan belajar siswa sehingga belajar sains tidak hanya sekedar menghafal. Namun juga sains yang bermanfaat dan manfaatnya dapat dirasakan langsung oleh siswa. 


\section{DAFTAR PUSTAKA}

Aikenhead, G. S., \& Jegede, O. J. 1999. Cross-cultural science education: A cognitive explanation of a cultural phenomenon. Journal of Research in Science Teaching, 36(3), 269-287.

Ndiken, I. Y. 2013. Etnolinguistik: Kamus Bahasa Malind Jilid I. Merauke: Tanpa Penerbit.

Osman, K., \& Har, E. 2013. Budaya Sains Asli dan Budaya Sains Modern dalam Kalangan Pelajar: Keselanjaran Usaha ke Arah Enculturation of Science Culture of Natural Science and Culture in the Modern Science among Students: Continuity Efforts towards the Enculturation of Science. Akademika, 82(2), 119-126.

Peday, A., Kanggam, W., Mahuze, Yosep, M., \& Ronggo, A. D. 2015. Kumpulan Cerita Rakyat Daerah Malind. Merauke: Dinas Kebudayaan Dan Pariwisata Kabupaten Merauke.

Poedjiadi, A. 2010. Sains Teknologi Masyarakat. Bandung: Rosda.

Prasetya, E. E. 2012. Wambad, Warisan Leluhur Merauke. KOMPAS.com.

Rahayu, E. W., \& Sudarmin. 2015. Pengembangan Modul IPA Terpadu Berbasis Etnosains Tema Energi Dalam Kehidupan Untuk Menanamkan Jiwa Konservasi Siswa. Unnes Scince Education Journal, 4(2).

Rosyidah, A. N., Sudarmin, \& Kusoro, S. 2015. Pengembangan modul IPA berbasis etnosains zat aditif dalam bahan makanan untuk kelas viii smp negeri 1 pegandon kendal. Unne Scince Educational Journal, 4(2), 563-569.

Samkakai, F. O., Hollenger, D., \& Ndiken, I. Y. 2013. TANAH MALIND Suatu Pendekatan Pemetaan Budaya Suku Bangsa. Merauke: Dinas Kebudayaan Dan Pariwisata Kabupaten Merauke.

Sarwanto, Budiharti, R., \& Fitriana, D. 2010. Identifikasi sains asli (indigenous science) sistem pranata mangsa melalui kajian etnosains. In Seminar Nasional Pendidikan Biologi FKIP UNS 2010 (pp. 229-236). FKIP UNS.

Sarwanto, Sulistyo, E. T., Prayitno, B. a, \& Pratama, H. 2014. Integrasi Budaya Jawa Pada Pengembangan Bahan Ajar Bumi Dan Alam Semesta. Jurnal Pendidikan Fisika Indonesia (Indonesian Journal of Physics Education), 10(1), 15-21.

Shidiq, A. S. 2016. Pembelajaran sains kimia berbasis etnosains untuk meningkatkan minat dan prestasi belajar siswa. In Seminar Nasional Kimia dan Pendidikan Kimia (SNKPK) VIII (pp. 227-236). Surakarta: UNS.

Suastra, I. W. 2010. Model Pembelajaran Sains Berbasis Budaya Lokal Untuk Mengembangkan Kompetensi Dasar Sains dan Nilai Kearifan Lokal di SMP. Jurnal Pendidikan Dan Pembelajaran, 43(2), 8-16.

Suja, I. W. 2011. Analisis Kebutuhan Pengembangan Buku Ajar Sains SD Bermuatan Pedagogi Budaya Bali. Jurnal Pendidikan Dan Pengajaran, 44(1-3), 84-92.

Supriyadi, Haeruddin, \& Nurjannah. 2016. Peningkatan kemampuan memecahkan masalah antara model penalaran kausal berbasis etnosains dan sains modern. JRKPF UAD, 3(2), 35-39. 
Tresnawati, N. 2018. Pembelajaran Sains Berbasis Kearifan Lokal dalam Upaya Peningkatan Konservasi Lingkungan pada Mahasiswa PGSD di Batik Tulis Ciwaringin Cirebon. Al Ibtida: Jurnal Pendidikan Guru MI, 5(1), 69-82. 